\title{
Acercamiento al estudio de la guerra mediática contra Cuba: representación de Cuba en 4 documentales de TVE
}

\author{
Manuel GonzÁLEz Ayestarán \\ Universidad Complutense de Madrid \\ mgayestaran@durik.es
}

Recibido: 20 de abril de 2014

Aceptado: 3 de septiembre de 2014

\begin{abstract}
Resumen
Cuba goza de un protagonismo en los medios de comunicación de masas que no se corresponde con la relevancia que este país tiene en el devenir político y económico mundial. La isla caribeña no representa una amenaza militar, ni tiene grandes reservas minerales o energéticas. Tampoco se registran muestras de violencia civil o policial significativas. Sin embargo son constantes las alusiones a su realidad política en los medios de comunicación.

En el presente trabajo se analiza la estrategia de representación de Cuba en una muestra de documentales de RTVE, teniendo en cuenta el contexto conflictivo en el que el país se encuentra desde el inicio de su proceso revolucionario con EE.UU., el cual cumple suficientes requisitos para ser considerado un conflicto de cuarta generación.
\end{abstract}

Palabras clave: Guerra mediática; propaganda; Guerras de cuarta generación; encuadre; comunicación.

\section{An approach to the study of media war against Cuba: Cuba's representation in 4 Televisión Española (TVE) documentaries}

\begin{abstract}
Cuba has a prominence in the world of media that does not correspond to its importance in the international political and economic development. This Caribbean island neither represents a military threat nor has big mineral or energetic reserves. Furthermore, there is no significant civil or police violence. However, references to its political reality are constant in the world of media.

In the present work, we analyze the media representation of Cuba in a sample of Radio Televisión Española (RTVE) documentaries, considering that the troubled relations that Cuba maintains with the U.S.A. since the beginning of its revolutionary process, could be considered as a fourth generation warfare.
\end{abstract}

Key words: Media war; propaganda; Fourth generation warfares; framing; communication.

\section{Referencia normalizada}

González Ayestarán, M. (2014) Acercamiento al estudio de la guerra mediática contra Cuba: representación de Cuba en 4 documentales de TVE. Historia y Comunicación Social. Vol. 19. Páginas 299-319. 
Sumario. 1. Introducción. 2. Cuba y EE.UU.: una guerra discreta. 3. Metodología. 3.1. Universo de análisis. 3.2. Estrategia de encuadre. 3.3. Método de análisis. 3.3.1. Indicadores vinculados a la variable selección temática. 3.3.2. Indicadores vinculados a la variable valoración. 3.3.3. Indicadores vinculados a la variable tono. 3.3.4. Indicadores vinculados a la variable encuadre noticioso. 4. Resultados. 5. Conclusiones. 6. Referencias bibliográficas.

\section{Introducción}

En el mundo actual, marcado por la globalización económica neoliberal liderada por EE.UU, las grandes corporaciones mediáticas juegan un papel determinante en la actividad política, íntimamente ligado a los poderes dominantes.

Los medios de comunicación actúan como mediadores sociales entre el sistema social del que forman parte y la realidad con la que éste interactúa, elaborando representaciones discursivas de la misma entendibles por el grueso de la sociedad, que contribuyan a la conservación del orden en el que se estructura dicho sistema social (Serrano, 2004: 135).

Así los medios de comunicación se erigen como agentes políticos en la medida en que su actividad es parte consustancial en la formación de las relaciones de poder que estructuran la sociedad. Según esta premisa, y concibiendo la guerra en términos de Karl Von Clausewitz como una extensión más de la política ordinaria, entendemos que los medios de comunicación de masas juegan un papel determinante en los conflictos bélicos, en absoluto menor al que desempeñan en los tiempos de paz como agentes políticos. En la actualidad, la batalla por la información antecede y complementa necesariamente al conflicto armado en el escenario mediático.

El filósofo alemán, admirador de Mussolini, Oswald Spengler, ya estableció en 1922 una conexión clave en la relación entre el conflicto bélico y los medios de comunicación cuando publicó el segundo tomo de su conocida obra La decadencia de occidente (1998: 713-714):

"La pólvora y la imprenta guardan una relación íntima [...]. La prensa es hoy un ejército, con armas distintas, cuidadosamente organizadas; los periodistas son los oficiales; los lectores son los soldados. Pero sucede aquí lo que en todo ejército: el soldado obedece ciegamente, y los cambios de objetivo y de plan de operaciones se verifican sin su consentimiento. El lector no sabe nada de lo que sucede y no ha de saber tampoco el papel que representa. No hay más tremenda sátira contra la libertad de pensamiento".

Esta sentencia, quizás desfasada en su concepción extremadamente pasiva de los públicos en el proceso comunicativo, -que Harold Laswell desarrollaría años después en su teoría de la Aguja hipodérmica- es actual, no obstante, en cuanto al papel que otorga a los medios de comunicación de masas, los cuales en las guerras modernas han ampliado sustancialmente su marco de actuación. En las formas de guerra 
propias de etapas previas a la globalización y al moderno desarrollo de las nuevas tecnologías de la comunicación, los mensajes mediáticos actuaban en gran medida como preámbulo del combate a la hora de configurar imaginarios colectivos acerca del "enemigo", que legitimaban posteriormente la materialización de la acción bélica en el campo de batalla. Hoy día juegan un papel más decisivo aún, según apuntan los nuevos estudios de ciencia militar, en un contexto en el que los frentes de combate tienden a desdibujarse, así como el conflicto en sí mismo, debido entre otras cosas al desarrollo global de las nuevas tecnologías de la comunicación (Ballesteros Martín, 2013: 13).

Las guerras modernas, catalogadas como guerras de cuarta generación, se caracterizan fundamentalmente por la "ampliación del campo de batalla a la totalidad de la sociedad enemiga" (Fojón, 2006: 2), siendo el ámbito cultural un objetivo clave en la pugna por el apoyo de la población civil del rival. Los ataques ahora buscarán anular el poderío militar enemigo dirigiéndose a su retaguardia civil en aras de desestabilizarla, mediante acciones terroristas, mecanismos de guerra sucia y fomento de la insurgencia. Ya no se trata únicamente de ocupar territorios con un ejército, sino de hacerse con el dominio de la población civil que otorga el control del terreno en cuestión (Ballesteros Martín, 2013: 16). El coronel José Enrique Fojón (2006.:2) llega a afirmar que:

\footnotetext{
"estas características configuran una situación en la que la frontera clásica entre guerra y paz se difumina, hasta el punto de ser difícil de determinar. Los contornos del campo de batalla resultan imprecisos, sin frentes identificables, y la distinción entre civiles y militares se vuelve muy tenue".
}

Este concepto de guerra de cuarta generación engloba gran parte de las operaciones militares posteriores a los años 50, desde la Guerra de Vietnam, o la de Afganistán, pasando por los numerosos episodios de guerra sucia impulsados por la inteligencia estadounidense por todo el Tercer Mundo (como la Operación Cóndor en Latinoamérica), hasta la actual "guerra contra el terrorismo". Este modelo es fruto del desarrollo de la globalización, marcado por el auge de las modernas tecnologías de la comunicación, las cuales posibilitan el acceso a información en tiempo real creando estados de opinión, tanto en las retaguardias civiles de los contendientes como en la comunidad internacional, que son determinantes en el desarrollo de los conflictos (Ballesteros Martín, 2013: 13).

\section{Cuba y EE.UU.: una guerra discreta}

En este escenario Cuba, con su régimen socialista de gobierno, queda a modo de resquicio de la antigua Guerra Fría erigiéndose como forma de desarrollo alternativo, contraviniendo diametralmente las órdenes de corte neoliberal emitidas por instituciones como el Fondo Monetario Internacional o el Banco Mundial, de cara a los países en vías de desarrollo. 
Desde el triunfo de la revolución en 1959, el país ha entrado en un conflicto con el gobierno de EE.UU. prolongado de manera ininterrumpida hasta el día de hoy, que entronca perfectamente con el concepto de guerra de cuarta generación antes descrito. El texto que se presenta a continuación es un extracto del memorándum enviado por Lester D. Mallory, subsecretario adjunto de Estado para los asuntos interamericanos de EE.UU., al entonces subsecretario de Estado para asuntos interamericanos Roy Rubottom Jr. el 6 de Abril de 1960, en el que se refleja claramente esa voluntad expansión del frente militar al grueso de la sociedad civil por parte del funcionario estadounidense:

"La mayoría de los cubanos apoya a Castro. No hay oposición política eficaz [... ]. El único medio posible para aniquilar el apoyo interno [al régimen] es provocar el desencanto y el desaliento por la insatisfacción económica y la penuria [... ]. Se deben emplear rápidamente todos los medios posibles para debilitar la vida económica de Cuba [... ]. Una medida que podría tener un fuerte impacto sería negar todo financiamiento o envío a Cuba, lo que reduciría los ingresos monetarios y los salarios reales y provocaría el hambre, la desesperación y el derrocamiento del gobierno". (Citado en Lamrani, 2013: 88)

Ese mismo año el presidente Eisenhower inició las primeras sanciones económicas contra la isla caribeña, además de una campaña de terrorismo y sabotaje mediante la financiación de movimientos paramilitares anticastristas que acabaron desembocando en el fallido intento de invasión que supuso la batalla de Playa Girón en 1961 (Ibid.: 29).

Apenas dos años después, el presidente Kennedy decretó el embargo total sobre Cuba, incluyendo medicinas y alimentos, contraviniendo el derecho internacional acordado en Ginebra en de 1949. Desde entonces el bloqueo, que dificulta de forma trascendental el desarrollo económico de la isla, debido entre otras cosas al carácter extraterritorial de su legislación (la cual afecta a terceros países y empresas mediante sanciones y prohibiciones comerciales con EE.UU en caso de que estos se relacionen con el gobierno cubano) ha sido mantenido hasta hoy de forma ininterrumpida. En 1991, coincidiendo con el peor período de crisis económica que atravesó el país desde el inicio del período socialista, el bloqueo se endureció mediante la aplicación de las ley Torriceli, y en 1996 mediante la ley Helms-Burton, con el fin empobrecer terminalmente a la sociedad cubana y derrocar definitivamente al gobierno (Ibid.: 54).

A esto hay que sumar el presupuesto público dedicado a la financiación de los diferentes movimientos de oposición interna con el fin de provocar el cambio de régimen en la isla, señalado en el artículo 1705 de la citada Ley Torriceli (Ibid.: 40), los cuales adquieren su dimensión más visible de cara al exterior en el terreno comunicativo.

Teniendo en cuenta este contexto, además de la afirmación antes citada del coronel Fojón (2006:2) relativa a difusión de las fronteras entre la guerra y la paz en los modernos contextos de conflicto bélico, la relación entre Cuba y EE.UU. se puede entender como una suerte de conflicto de cuarta generación de más de 50 años de 
duración, lo que nos lleva a considerar de gran trascendencia el estudio de la guerra mediática en el que éste se manifiesta.

Reseñar todos los episodios históricos que evidencian la existencia de esta guerra mediática sobrepasa las aspiraciones de este artículo, no obstante consideramos necesario nombrar cuatro de ellos especialmente significativos que han tenido lugar recientemente, a modo de ejemplo ilustrativo del contexto comunicativo en el que se sitúa el presente estudio.

Por parte del gobierno estadounidense y sus aliados en América Latina y Europa, así como de las grandes multinacionales mediáticas afincadas en estos territorios, destaca especialmente el apoyo brindado a grupos de opositores cubanos como las Damas de blanco o el Movimiento cristiano de liberación, otorgando gran difusión a sus consignas y creando mitos de la libertad en torno a sus líderes. Oswaldo Payá, recientemente fallecido en un accidente de coche, o la bloguera Yoani Sánchez, la cual llegó a ser contratada como corresponsal por parte del diario El País en La Habana en 2012, y fue nombrada vicepresidenta en 2007 de la Sociedad Interamerica de Prensa (El Nacional, 09/11/2012), son algunos ejemplos de celebridades en la lucha por la supuesta libertad en Cuba.

Recientemente también, ha tenido lugar la creación de la red social "Zunzuneo", proyecto gestionado por la Agencia Internacional de Estados Unidos para el Desarrollo, cuyo fin era agitar a la juventud cubana, mediante la difusión de mensajes subversivos a través de esta plataforma, con el fin de provocar una "Primavera cubana" que desestabilizase al gobierno (El País, 03-04-2014).

Por su parte, el gobierno cubano impulsó en 2003 una iniciativa en internet creada por un grupo de estudiantes universitarios que desembocó en el portal de información "Cubadebate", el cual actúa en la red a modo de contrapeso informativo con ideología afín al gobierno cubano. A su vez, desde el exterior, la asociación "Solidaridad con Cuba" impulsó el proyecto informativo "Cubainformación", que se define a sí mismo en su slogan como "una brecha en el bloqueo mediático", consigna que manifiesta el carácter conflictivo de las relaciones entre la Isla y los medios de comunicación exteriores.

Como puede apreciarse, el conflicto entre la primera potencia mundial y la isla caribeña tiene múltiples escenarios, siendo en la actualidad prácticamente imperceptible su dimensión propiamente militar. No obstante, la batalla por la hegemonía informativa tiene lugar a diario en los grandes medios de comunicación de masas, así como en los diferentes portales informativos y contrainformativos de Internet.

En este marco mediático se hace especialmente interesante el análisis del discurso emitido por los medios de comunicación españoles sobre la realidad sociopolítica cubana a sus públicos, un tema nunca abordado hasta ahora en el ámbito académico español.

En un estudio sobre la representación de Latinoamérica en la prensa española (perteneciente a un proyecto más amplio acerca del tratamiento informativo de la 
inmigración), llevado a cabo por María Luisa Humanes y Juan José Igartúa, se señaló que Cuba aparece, tras Chile, como el segundo país más nombrado en los periódicos españoles analizados (El Mundo, El País, La Vanguardia, y ABC), y el primero en el índice de importancia creado por ambos autores para codificar la relevancia que los diarios le conferían a cada nación según el emplazamiento que reservaban a las noticias que tratasen sobre su realidad (2004: 64). Así las noticias sobre Cuba ocupaban emplazamientos privilegiados en comparación con las relativas al resto de países del continente, lo que manifiesta un interés especial por parte de los medios de comunicación españoles en informar sobre esta isla.

Cabe reseñar el papel trascendental que tienen estos mediadores sociales a la hora de informar sobre la realidad cubana a sus públicos, ya que, debido a la lejanía geográfica de ambos países, y al posicionamiento marginal de las fuentes alternativas de información en el mercado mediático, el discurso de los grandes medios de comunicación se convierte en el principal canal informativo sobre esta realidad de cara al público español.

\section{Metodología}

\subsection{Universo de análisis}

El presente estudio es de corte cualitativo, en él se pretende realizar un análisis de contenido de cuatro documentales producidos por Radio Televisión Española sobre la isla caribeña, con el fin de identificar las claves que guían la representación de su realidad que la cadena, en su papel de mediador social, ofrece a la sociedad española.

Los cuatro documentales que comprenden la población de análisis son:

1. "Cuba, Luces y Sombras": Es un documental televisivo perteneciente al formato "En portada", dirigido en 2006 por el periodista Juan Antonio Sacaluga, y producido por el Ârea de producción de programas informativos de Televisión Española.

2. "Cuba, la Revolución reinventada": Es, como la anterior pieza, un documental televisivo perteneciente al formato "En portada", producido por la periodista Ana Pastor en 2012.

3. "Cuba, directa al corazón": Es un documental televisivo perteneciente al formato "Paraísos cercanos", emitido por primera vez en 1998 y re-emitido en 2010 .

4. "Españoles en el mundo, La Habana": Documental televisivo perteneciente al formato "Españoles en el mundo", emitido por la cadena en 2011.

Se han elegido los documentales de forma que se puedan analizar los dos tipos de discurso más recurrentes en las representaciones que desde el Norte del mundo 
se tiende a hacer del Sur: la óptica político-económica, mediante que se representa un Sur pobre, fuente de miseria y catástrofes (Fueyo, 2002: 51); y la óptica turística mediante la que se retrata un Sur paradisiaco, fuente de placer y ocio para el consumidor del Norte (Ibid.: 87). Las dos piezas pertenecientes al formato "En portada" ofrecen el primer enfoque representativo, y "Cuba, directa al corazón" y "Españoles en el mundo: la Habana" el segundo.

La selección de estas piezas audiovisuales no tiene una pretensión representativa de la imagen general creada en TVE sobre Cuba, ya que los documentales han sido seleccionados conforme a criterios estrictamente funcionales de accesibilidad y disponibilidad de la muestra. No obstante entendemos que, siendo material producido por la propia cadena pública de televisión, cumple ciertos estándares de representación que, a nivel tanto ideológico como discursivo, se enmarcan dentro de la óptica dominante desde la que se retrata la realidad cubana en los grandes medios de comunicación de masas españoles.

\subsection{Estrategia de encuadre}

El método de estudio elegido es el análisis de contenido llevado a cabo mediante el modelo teórico del "framing" o estrategia del encuadre, siguiendo el modelo empleado por María Luisa Humanes y Juan José Igartúa para su estudio antes citado relativo a la representación de Latinoamérica en la prensa española (Igartúa, 2004: 57).

Esta estrategia de análisis parte del concepto de encuadre noticioso, el cual hace referencia a dos dinámicas clave de la producción del discurso informativo: la selección temática de la información y su organización discursiva. La primera consiste en la selección de las facetas de la realidad elegidas por el medio para ser representadas, y la segunda, en la serie de filtros interpretativos que definen la óptica del periodista, a través de los cuales éste construye la representación final que llega al público (López, 2010: 239).

Mediante la elección de este sistema de análisis pretendemos analizar qué se dice de Cuba y qué no se dice, así como las relaciones discursivas que producen el producto final mediante el cual el público se informa de una realidad tan lejana y, en ciertos aspectos, tan hermética.

\subsection{Método de análisis}

La dinámica de análisis consiste en el volcado de la información de cada documental, llevando a cabo una división de su discurso según criterios temáticos. Con ello se tratará de señalar qué aspectos de la realidad cubana son mostrados en cada pieza, identificando en cada documental un tema general, vertebrador del discurso, y los diferentes subtemas que representan los aspectos de la realidad cubana seleccionados por los realizadores, los cuales constituirán nuestras unidades de análisis. Una vez volcada la información según este marco operativo se procederá a su procesamiento atendiendo a 4 variables: la selección temática que realizan, la consiguiente valora- 
ción de cada tema, el tono empleado al representarlos, y el encuadre noticioso. Las cuales se definirán según los siguientes indicadores:

\subsubsection{Indicadores vinculados a la variable selección temática}

Se manejan cinco categorías en las que se agrupan los diferentes subtemas tratados en cada documental: Economía, política, estilos de vida, cultura, y ocio. La frecuencia con la que aparece cada una viene definida por el número de subtemas tratados en cada documental que se adscriben a ella.

Es necesario señalar que en muchos casos, la atribución de un subtema concreto a cada categoría no es un ejercicio exacto, un mismo subtema podría ser adscrito a varias categorías simultáneamente, ya que éstas no son cerradas, pero dada la naturaleza del presente trabajo solo se adscribirá a una. La selección de la categoría más adecuada para cada subtema ha sido fruto del criterio del investigador, elaborado atendiendo a dos variables fundamentales: el tema transversal del documental con el que conecta el subtema concreto en cuestión y el predominio explícito del objeto temático retratado en el discurso audiovisual, en forma de imágenes y palabras del narrador.

De esta forma, un subtema que versa sobre los efectos de la economía en la vida de los cubanos, expresado a través de anécdotas curiosas de la vida en carestía de los mismos con tono alegre y distendido en el documental turístico "Cuba, directa al corazón" (1998), se adscribe a la categoría "estilos de vida" y no a la de "economía", ya que en entronca con el tratamiento transversal que se da a la realidad cubana en el documental, al representarla como un curioso objeto de consumo para el turista. En cambio, un subtema como el referente a los sueldos en Cuba, abordado en el documental "Cuba, luces y sombras" (2006), en el que el narrador se refiere a las remesas enviadas a los ciudadanos cubanos por parte de sus familiares residentes en el extranjero, que suponen un ingreso esencial para ellos debido a la insuficiencia de los sueldos, es adscrito a la categoría "economía" y no a la de "estilos de vida", debido a que se aborda en relación al tema transversal del documental que es el análisis del sistema sociopolítico de la isla.

\subsubsection{Indicadores vinculados a la variable valoración}

Se evaluará en qué medida en la cobertura de cada subtema se lleva a cabo una valoración en términos favorables o desfavorables. Se catalogará como una cobertura favorable o positiva el tema que sea presentado de forma atractiva o deseable para el público, y como desfavorable o negativa cuando el mismo sea presentado de forma nociva, partiendo de que el público medio del documental está formado por ciudadanos de un país primermundista, regido por un sistema político de democracia liberal. 


\subsubsection{Indicadores vinculados a la variable tono}

Dos categorías se han desarrollado para evaluar el tono en el que se aborda cada tema en función de los recursos propios del lenguaje audiovisual empleados a la hora de presentarlo (tales como la música que lo acompaña o las imágenes que se muestran). Éste podrá ser: distendido, si la sensación evocada al tratarlo es amena y agradable, o dramático si ésta se torna tensa o desagradable.

\subsubsection{Indicadores vinculados a la variable encuadre noticioso}

En este apartado se analizará el discurso respecto a las claves de organización discursiva empleadas por el realizador en la presentación de cada tema. La tipología de encuadres seleccionada es la empleada por Humanes e Igartúa en su estudio antes citado (Igartúa, 2004: 56), de forma adaptada a nuestro objeto material de estudio. Ésta incluye cinco tipos de encuadres, más uno extra creado por nosotros para identificar claves de nacionalismo banal impresas en el discurso de RTVE:

1.- Encuadre de interés humano: Se entenderá que predomina este encuadre cuando el discurso esté construido en función de realzar la faceta humana y emocional del tema abordado, ilustrándose éste mediante la incursión en la vida privada de algún individuo a modo de ejemplo de caso, o incluyendo testimonios vitales de sujetos afectados por el tema o problema abordado.

2.- Conflicto: Se seleccionará el encuadre de conflicto como predominante en el tratamiento de un subtema cuando se represente éste abordándose dos o más posturas contradictorias respecto al mismo.

3.- Consecuencias de la economía: entendemos que este encuadre predomina cuando se aborda un subtema haciendo referencia a las condiciones económicas de las que es resultado.

4.- Atribución de responsabilidad: entendemos que predomina este encuadre cuando un subtema se presente fijando a alguna institución o individuo como causante del mismo, o con capacidad para actuar sobre él.

5.- Moralidad: predomina el encuadre de moralidad cuando se haga referencia a algún tipo de valoración de un tema conforme a una serie de principios éticos o religiosos, así como cuando se haga referencia a un modelo social de actuación.

6.- Nacionalismo banal: se identificarán muestras de nacionalismo banal en dos casos: cuando en el discurso se haga referencia al pasado colonial cubano, dejando implícito el sello identitario español presente hoy en Cuba, o cuando se realicen comparaciones entre la realidad sociopolítica cubana y la española en clave de similitud o diferenciación, evaluando la posición de superioridad, inferioridad o neutralidad que se construye en el discurso entre ambas naciones.

Por último, en el caso de los dos documentales pertenecientes al formato "En Portada" se realizará un recuento de los testimonios de individuos entrevistados que 
se aportan, con el fin de evaluar si existe un posicionamiento ideológico concreto al que se otorgue un mayor espacio discursivo. Esto es debido a que el formato, de temática predominantemente política, emplea como recurso narrativo numerosas intervenciones de cubanos claramente posicionadas ideológicamente que entran en conflicto entre sí. Este recuento no se realizará en los documentales turísticos, ya que los individuos entrevistados en estas dos piezas no tienen una posición política clara, debido a que el tema vertebrador de los documentales no es manifiestamente político.

\section{Resultados}

A la hora de valorar los resultados de nuestra investigación, partimos del enfoque propuesto por Edward W. Said, en su obra "Orientalismo" (2002: 25), según el cual la dominación del Norte occidental sobre el resto del mundo se manifiesta en las descripciones o estudios sociales que se elaboran desde esa posición de poder acerca de las sociedades dominadas:

Así según este autor, desde la posición dominadora de la potencia económico-militar, se elaboran representaciones de las sociedades dominadas que justifican esa relación de poder. Hablando por ellos, el colonizador les describe de una forma funcional a sus propios intereses de dominio, atribuyéndose la capacidad de elegir por ellos lo que más les conviene (Ibid.: 62). Desgranando la representación realizada de Cuba en los cuatro documentales seleccionados, observamos esa voluntad por parte de sus realizadores, creadora de una realidad cubana necesitada de políticas de corte liberal que la igualen con el resto de países en vías de desarrollo en su camino hacia el progreso, entendido éste en los términos propios de una sociedad de mercado.

A continuación describiremos el contenido de los documentales agrupándolos según sus dos principales enfoques vertebradores:

\section{1.- Representación de la "cárcel Cuba"}

En este apartado procederemos a describir en clave dialógica la estrategia discursiva seguida por los documentales "Cuba, la revolución reinventada" (2012) y "Cuba, sombras y luces" (2006), ya que son los que retratan la realidad cubana en clave manifiestamente sociopolítica, con esquemas narrativos idénticos.

En "Sombras y luces" (2006) se retrata el país en el momento de la adquisición por parte de Raúl Castro del cargo de jefe de estado temporalmente, debido a temas vinculados a la salud de Fidel. Así, se muestra un país asolado por apagones, cartillas de racionamiento, sueldos escasos, detenciones, y educación doctrinaria, que llega por fin a un momento histórico debido a la ausencia de Fidel Castro, en el que se abren dos posibles caminos: la preservación del socialismo o la transición a la democracia liberal. 
"La revolución reinventada" (2012) realiza de manera similar un repaso crítico de la realidad sociopolítica de la isla, esta vez con motivo de las reformas económicas impulsadas por Raúl Castro en 2011, mediante las que el gobierno permitió la existencia de pequeñas empresas de gestión privada a cargo de los llamados "cuentapropistas" (trabajadores autónomos). En el documental se valoran negativamente dichas reformas, entendidas como insuficientes e intrascendentes de cara al cambio político. Aún así no dejan de verse como posibles desencadenantes de un cambio social más profundo en la población cubana que acabe "abriendo" el sistema socialista hacia la democracia liberal.

Como puede observarse, es la identificación del posible detonante del cambio de sistema político lo que motiva la realización de ambos documentales. En ellos se configura el discurso que denominamos la "cárcel Cuba" en el que se representa a una sociedad civil demandante de políticas de libre mercado, presa a su vez de las voluntades de una oligarquía estatal incapaz de conducir al país hacia el desarrollo económico, quedando los aspectos relativos al conflicto de antes descrito entre Cuba y EE.UU. totalmente ignorados.

Erigiéndose como portavoces de la mayoría de los cubanos, los respectivos narradores de ambos documentales pronuncian frases en las que describen una voluntad generalizada de cambio de sistema político presente en la sociedad, configurando una relación dialéctica entre ésta y sus gobernantes. Afirmaciones como "hay ganas de cambio en la sociedad" en el caso de "La revolución reinventada" (min. 45), o "nunca ha habido tanta esperanza de que las luces finalmente se abran camino entre las sombras", pronunciada por el narrador de "Sombras y luces" (min. 02:10), denotan ese supuesto consenso existente en la sociedad civil cubana acerca de la necesidad de transformación del sistema político del país.

Tras sus respectivas introducciones, ambos documentales se desarrollan abordando diferentes temas referentes a la situación político-económica de la isla mediante la voz vertebradora del citado narrador, apoyada por entrevistas a personalidades del gobierno, de la oposición, así como a ciudadanos cubanos que completan la elaboración del discurso. Se ha observado que los diferentes testimonios aportados por las personas entrevistadas están claramente posicionados en función del rol que se atribuye a cada uno en el documental, indicado por la etiqueta identificadora que se les otorga al presentarles. Así las intervenciones de los cargos gubernamentales son en su totalidad favorables al socialismo, las de los opositores contrarias, y las del resto de ciudadanos imparciales (estas últimas tienen un carácter meramente testimonial acerca de formas de vida del cubano medio, y en ningún caso son valorativas).

Realizando un recuento del número de intervenciones, hemos advertido en ambos documentales una acusada presencia de testimonios pertenecientes a diversos movimientos de oposición al gobierno, en comparación con las relativas a personas afines al mismo. Concretamente en "Sombras y luces" (2006), encontramos 29 intervenciones a cargo de opositores, frente a 10 por parte de funcionarios socialistas. En "La revolución reinventada" (2012) las intervenciones críticas ascienden a 20, quedando 
en 5 las de trabajadores afines a Castro. Como se puede observar, en ambos documentales se da una abultada preeminencia del discurso anticastrista.

Esta tendencia también se observa en la variedad de individuos entrevistados de cada grupo, estando compuesto el de opositores por 15 personas en "Sombras y luces" (2006) y 7 en "La revolución reinventada" (2012), frente a los 3 miembros afines gobierno que intervienen en ambos documentales. Esta selección de testimonios contrapuestos, tiene una clara significación que se desdobla en dos dimensiones. En primer lugar evidencia la voluntad manifiesta de sesgar la versión que se da de los acontecimientos en favor del enfoque de talante liberal, propio de los opositores, silenciando en gran medida los argumentos justificadores de las actuaciones del gobierno.

En segundo lugar, la acusada diferencia presente en el número de personas seleccionadas para cada grupo de entrevistados, en favor de los opositores, sobredimensiona la presencia de las posiciones liberales en el debate político cubano, representando las posiciones socialistas como una minoría solo presente en los cargos gubernamentales.

Se configura así, en la propia estructura narrativa de los documentales, esa dialéctica gobierno-población civil que vertebra el discurso de la "cárcel Cuba", extendiendo la postura ideológica de la oposición cubana al grueso de la sociedad.

Respecto a la forma de tematizar el contenido, se han identificado 11 subtemas tratados en cada documental, la mayoría vinculados a la categoría temática "política", siendo la única existente en "Sombras y luces" (2006), y complementándose con la relativa a "economía" en "La revolución reinventada" (2012). Destaca el hecho de que en ambos documentales se realiza una valoración negativa de la totalidad de los subtemas tratados, de los cuales cinco son abordados en las dos piezas (alimentación de la población, sistema de dualidad monetaria, actividad de los cuentapropistas, derechos humanos y bloqueo económico).

El encuadre predominante en ambos discursos es el de atribución de responsabilidad, ya que siempre se relaciona la valoración negativa de cada tema con la actividad del gobierno del país, excluyendo cualquier condicionante externo. Esta estrategia es determinante en la medida en que oculta la influencia de factores de naturaleza histórica y política que afectan a la situación socioeconómica de Cuba, tales como el conflicto antes descrito existente entre ésta y EE.UU., o las variables relativas al pasado colonial y neocolonial cubano, cuya influencia en su estatus actual de país en vías de desarrollo son significativas.

Por ello, la forma en la que se hace referencia al bloqueo económico en ambas representaciones de Cuba merece especial mención en este análisis.

En "La revolución reinventada" (2012), la representación de esta medida se articula mediante el encuadre de conflicto, contrastando diversos argumentos. En primera instancia se describe como una "losa" en la economía cubana condenada por la ONU pero, por otro lado, se hace especial hincapié en los aspectos no restrictivos 
del mismo en las relaciones cubano-estadounidenses. Finalmente se acaba entrevistando a un economista opositor que lo califica como la "gran coartada" del gobierno cubano, en la medida en que es usado para opacar sus políticas obstaculizadoras del desarrollo interno del país (min. 36:20).

En el caso de "Sombras y luces" (2006) el tema se cataloga directamente como una mala estrategia por parte de EE.UU. debido a que alimenta ideológicamente al gobierno cubano. De esta forma se ignora el impacto que esta medida tiene y ha tenido desde su imposición en 1962 en la economía cubana, resaltando sus aspectos menos restrictivos en el caso de la "Revolución reinventada" (2012), y otorgando en ambos casos un papel preferente al discurso de la oposición, mediante el que se lo hace pasar como una suerte de beneficio para el gobierno, en vez de un obstáculo.

Por otro lado, consideramos también necesario resaltar el tratamiento negativo que se hace de temas como la alimentación de la población, la medicina o la educación, en los que Cuba siempre ha despuntado en comparación con el resto de países en vías de desarrollo.

En ambos documentales se enfoca el tema de la alimentación como un grave problema en Cuba. En "Sombras y luces" (2006) se hace especial hincapié en la frugalidad de la libreta de racionamiento impuesta por el estado (min. 04:30), y en "La revolución reinventada" (2012), además de este aspecto, se resalta también el carácter ineficiente de la industria agropecuaria nacional a la hora de alimentar a toda la población (min. 34:10).

De nuevo, haciendo uso del encuadre de atribución de responsabilidad, se obvian las dificultades que atravesó el país hasta 2007 debido a la crisis económica conocida como el "Período especial", provocada por la caída de la URSS, durante la cual Washington aprovechó para hacer caer definitivamente al gobierno socialista cubano endureciendo el bloqueo. En este período Cuba perdió su principal suministro de petróleo, paralizándose por tanto gran parte de su transporte motorizado, así como su producción agrícola intensiva, y la población redujo su ingesta diaria per cápita en más de 1000 calorías de media (Franco et al., 2007: 1376). En 2001 la sociedad cubana ya había recuperado los niveles alimenticios anteriores a esta crisis, y en 2009 UNICEF la ha declarado el único país de Latinoamérica libre desnutrición infantil (BBC Mundo, 26/01/2010).

Teniendo en cuenta esta evolución en circunstancias adversas, se hace evidente la forma en la que, mediante la estrategia de encuadre adoptada en ambos documentales, se hace pasar como un fracaso del gobierno cubano su evidente progreso respecto a los países de su misma categoría socioeconómica.

Por otro lado, la medicina y la educación, calificadas como "orgullos del régimen" en "Sombras y luces" (2006, min. 09:45), no aparecen siquiera nombradas en "La revolución reinventada" (2012). En el documental dirigido por Juan Antonio Sacaluga ambas son valoradas negativamente haciendo referencia al uso político que se les da desde el gobierno. En el caso de la medicina se hace referencia a su instru- 
mentalización en las relaciones con la Venezuela bolivariana, y en el de la educación a su carácter doctrinario. Ambos logros aparecen representados como instrumentos políticos de Fidel Castro, evitando nombrar hechos básicos, como la gran cantidad de médicos que exporta Cuba al exterior en misiones humanitarias, la accesibilidad gratuita de ambos servicios para toda la sociedad, o el índice residual del $0,2 \%$ de analfabetismo que tenía el país en 2011(The World Factbook, 2011).

Por último, consideramos necesario hacer referencia a otro tema clave en la estrategia discursiva creadora de la representación de la "cárcel Cuba": los derechos humanos. Su tratamiento se lleva a cabo en ambos documentales haciendo uso del encuadre de interés humano, otorgando pleno protagonismo a los testimonios de figuras de la oposición, como Oswaldo Payá, las Damas de blanco o Yoani Sánchez, en las que se acusa al gobierno de violar numerosos derechos básicos con aquellos ciudadanos que esgrimen opiniones divergentes a la oficial.

Observamos que mediante esta estrategia discursiva se elude indagar en las formas de subsistencia y financiación de estos movimientos opositores, las cuales suponen una clave contextual determinante para la comprensión del tema. En declaraciones públicas realizadas por estas mismas figuras de la oposición cubana, así como por organizaciones internacionales que los defienden como Amnistía Internacional, e incluso por el propio gobierno estadounidense en sus documentos legislativos, se admite el hecho de que su financiación viene en gran medida proporcionada por parte del gobierno estadounidense (Rebelión, 22/12/2010). Este hecho es relevante porque ningún país del mundo, inmerso en un contexto conflictivo como el existente entre Cuba y EE.UU., aceptaría dentro de su propia jurisdicción un movimiento opositor financiado por el gobierno enemigo. Relativo a esto es significativa la afirmación del ex-embajador estadounidense en Cuba Wayne S. Smith en la que afirma que

"[...] cuando Estados Unidos declara que su objetivo es derrocar al gobierno cubano y después afirma que uno de los medios para lograrlo es proporcionar fondos a los disidentes cubanos, éstos se encuentran de facto en la posición de agentes pagados por una potencia extranjera para derrocar a su propio gobierno" (Citado en Ibid. 22/12/2010).

Eludir este aspecto de la realidad al tematizar el discurso indudablemente da como resultado una información incompleta que dirige la comprensión de la realidad sociopolítica cubana hacia unos patrones ideológicos muy evidentes.

Mediante este tipo de mecanismos se articula el discurso de la "cárcel Cuba", cuya estrategia de representación se desdobla, como se ha observado, en tres dinámicas fundamentales:

En primer lugar, valorar de manera negativa todo aspecto de la sociedad cubana seleccionado al tematizar el contenido del discurso, resaltando los aspectos más desfavorables del mismo y obviando, o minimizando, los que puedan ser considerados más favorables. 
En segundo lugar, emplear de manera reiterativa el encuadre de atribución de responsabilidad hacia el gobierno cubano en cada tema tratado, obviando factores como la evolución histórica del país desde los tiempos de la colonia, así como la situación de relativo estado de sitio en la que éste que se encuentra, debido a su relación conflictiva con la primera potencia mundial durante el último medio siglo.

En tercer lugar, descontextualizar la realidad cubana de la de su entorno geopolítico próximo, valorando su nivel de bienestar desde la óptica del visitante proveniente de una potencia económica, en vez de adoptar la propia del de un país en vías de desarrollo.

En cuarto lugar, otorgar un espacio discursivo acusadamente superior a las posiciones ideológicas de los movimientos de oposición al gobierno respecto a las afines a él, sobredimensionando sutilmente su acogida en el conjunto de la sociedad cubana.

\section{2.- Representación del "paraíso Cuba"}

En este apartado se procederá a describir la representación de Cuba realizada en los documentales "Cuba, directa al corazón" (1998) y "Españoles en el mundo, La Habana" (2011), los cuales comparten la óptica turística como eje vertebrador sus discursos. Mediante esta óptica, se tiende a destacar aquellas facetas de la realidad de la isla consumibles por el turista de tales como lugares para visitar, productos que comprar, actividades de ocio para realizar, etc (Fueyo, 2002: 87).

La estructura narrativa de "Cuba, directa al corazón" (1998) se construye mediante la voz en off de un narrador que da sentido al montaje de imágenes, acompañado en todo momento de música extradiegética. En el caso de "Españoles por el mundo" (2011), el discurso se articula mediante seis entrevistas a españoles que residen en Cuba, en las que cada individuo muestra una parte concreta de la isla haciendo referencias a la historia y al estilo de vida propio del lugar, así como a diferentes facetas de su vida privada vinculadas con su experiencia migratoria. El formato, creado en 2009 al poco de iniciarse oficialmente la crisis económica en España, se dedica a describir casos exitosos de emigración de españoles representando esta necesidad, fruto de la precariedad en la mayoría de los casos, como una fuente de oportunidades.

En ambos documentales se da una característica temática común que resalta especialmente: la sobredimensión del vínculo histórico y cultural existente entre Cuba y España. En este sentido, se observan reminiscencias de un discurso nostálgico vinculado a la "pérdida de la última colonia» (López García, 2001: 803) de principios del siglo pasado, en lo que se convierte en una búsqueda de los restos de la presencia española en la isla.

En "Cuba, directa al corazón" (1998) se describe la isla como un lugar "congelado en el tiempo", el narrador afirma que "además de nostalgia, Cuba es también alegría y color" y se llega a referir a la época de la colonia como "aquel momento mágico" (min. 54:50). En el caso de "Españoles en el mundo" (2011) son constantes además las afirmaciones referentes a la especial compatibilidad de las relaciones entre espa- 
ñoles y cubanos en frases como "Cuba es una prolongación de España" (min. 09:03) o "Cuba recibe muy bien a los españoles sobre todo" (min. 27:36).

Ambos discursos coinciden en esa voluntad de retratar la "hispanidad" que aún está presente en la isla caribeña, prueba de paternidad de la antigua metrópoli sobre su ex-colonia. En este sentido, son constantes las referencias a los diferentes lugares de arquitectura colonial como La Habana vieja, o la fortaleza de "El morro", donde aún quedan conservados los restos del imperio perdido.

Al pertenecer a formatos más vinculados al entretenimiento que los anteriores, estas piezas se caracterizan por tener un discurso de tono distendido destinado a mostrar una Cuba agradable para el público, por lo que la mayoría de temas abordados suelen tener una valoración positiva. No obstante, esta visión positiva es en relación a una Cuba objeto de consumo para el ciudadano español, y no está exenta de referencias negativas al sistema sociopolítico del país que entroncan con el tipo de discurso descrito en el epígrafe anterior.

En "Cuba, directa al corazón" (1998), haciendo referencia al malecón de La Habana como atracción turística, se habla de cubanos que "arriesgan su vida [pescando en la bahía en barcas improvisadas] con tal de traer algo de pescado a casa" en una ciudad que "se manifiesta marinera en la que, paradójicamente, el pescado tiene poca presencia" (min. 12:33). Más adelante, al representar la Plaza de la revolución, "donde tiene lugar la vida política del país" (min. 09:42), se cambia el tono distendido del documental por un tono tenso, con música disonante, y un efecto sonoro de voces distorsionadas, evocando una sensación de tormento y encierro que conecta con el discurso de la "cárcel Cuba" antes descrito.

Estos ejemplos son algunos de los recursos discursivos mediante los que se construye la representación de la realidad sociopolítica cubana en clave de fracaso, en la que resalta el hecho de que, habiéndose emitido el documental en 1998, se haga especial hincapié en aspectos como la precariedad del transporte o en la insuficiencia energética, sin hacer referencia alguna al Período especial por el que entonces estaba pasando el país.

De los 19 subtemas tratados en "Cuba, directa al corazón" (1998) la mayoría se vinculan a las categorías de "cultura" y de "estilos de vida", ya que el documental muestra atractivos turísticos en la isla y varios aspectos de las formas de vida de los cubanos. Sin embargo, al evaluar los encuadres, observamos que 5 de los 7 subtemas referidos a "estilos de vida" se corresponden con el encuadre de "consecuencias de la economía", además de 2 subtemas referidos explícitamente a la economía del país y 1 al sistema político, valorados negativamente.

Por otro lado, 4 de los 5 subtemas agrupados en la categoría "cultura" aparecen representados bajo el encuadre de nacionalismo banal, en su mayoría haciendo referencia nostálgica al pasado colonial de la isla.

Por otro lado, la visión que se realiza del cubano entronca con el imaginario del Sur producido fundamentalmente por la industria de la publicidad, según el cual 
predomina el estereotipo del "pobre feliz", construido mediante la acentuación su carácter festivo vinculado al baile y la música. Esta connotación le aleja por omisión de las tareas productivas vinculadas a la economía y la política, en las que éste por tanto es normal que fracase (Fueyo, 2002: 88). "Aquí la música no solo se entiende, también se vive [...] [los cubanos] convierten su vida en fiesta cualquier día gracias a la espontaneidad de su gente (min. 30:50), "la impresión que recibe el viajero es que viven a la espera de algo que no llega [...] (min. 34:50)" son algunas de las múltiples expresiones hechas por el narrador del documental, en las que se remarca el talante ocioso y pasivo de los cubanos.

En el caso de "Españoles en el mundo" (2011), observamos también una representación favorable de Cuba vehiculada por los testimonios de los inmigrantes españoles, en la que estos muestran la mejor faceta de su vida allí, así como los enclaves de mayor interés turístico, haciendo constantes referencias a los aspectos que extrañan de España. De nuevo la valoración positiva de la realidad cubana creada en el documental se evalúa en función de lo que el país ofrece al español, y no en lo propiamente cubano.

En esta pieza es en la que menos referencias explícitas a la política del país hemos encontrado, debido principalmente a que el tema vertebrador del documental es la experiencia migratoria de los entrevistados, representada bajo el encuadre de "interés humano". Aún así se ha observado que las escasas referencias que se realizan a la política y la economía cubanas entroncan con las del resto de piezas de la muestra.

En consonancia con esto, la categoría temática predominante según nuestra clasificación es la de "estilos de vida", presente en 32 de los 48 subtemas identificados. Las referentes a "política" y "economía" aparecen en 4 casos la primera y 1 la segunda, correspondiéndose con el encuadre de "atribución de responsabilidad", mediante el que se apunta al gobierno cubano como causa principal de lo referido en esos temas. Por otro lado, en referencia a los encuadres, además del relativo a "interés humano" antes señalado, presente en 26 de los 48 casos, destaca el de "nacionalismo banal" en 15 de ellos, en forma de alusiones a la época colonial y de comparaciones entre España y Cuba, en las que la última solo sale beneficiada en el caso del prestigio del que goza la danza en la sociedad.

La mayoría de subtemas se valoran de forma positiva salvo cinco de ellos que se corresponden con los que apuntan a la política o la economía de la isla, bien mediante el tema que tratan o el encuadre desde el que se aborda. En el minuto 36:40, por ejemplo, se hace referencia a la educación y a la medicina del país de nuevo como «grandes logros de la revolución» sin desarrollar exactamente a qué se debe esta calificación, e inmediatamente se destacan aspectos como las grandes necesidades que aún tiene la población, o los sueldos escasos que reciben los cubanos, elaborando una valoración final negativa del sistema político.

Por tanto, el discurso del "paraíso Cuba" se construye en estos documentales seleccionando aspectos de la realidad de la isla, vinculados a las categorías de "cultura" y "estilos de vida", y haciendo un uso mayoritario de los encuadres de "interés humano" 
y de "nacionalismo banal", mediante los que se tiende a destacar los vínculos existentes entre España y Cuba derivados de la época colonial, así como los restos del imperio español aún presentes en la isla.

A su vez, en ambas piezas se retrata el paraíso de sol y playa que el país ofrece al turista, así como los productos que Aquilina Fueyo ha calificado como "paradigmáticos de la explotación colonial" (2002: 97), como son el ron, el tabaco y el azúcar de caña, que éste puede consumir en su viaje.

Por otro lado, en lo referente a lo exclusivamente cubano, en ambos documentales se hace referencia al supuesto fracaso político de la experiencia revolucionaria, observable en la precariedad material en la que viven los cubanos (transporte viejo, fachadas de edificios en ruinas, etc.), así como al carácter feliz y pasional de estos, representados con especiales dotes para la música y el baile. "Cuba es playas, sol y música pero también seres humanos" (Cuba, directa al corazón, min 55:06), "un país donde la vida corre como en ningún otro sitio" (Españoles en el mundo, min. 01:00), ambos documentales están llenos de este tipo de afirmaciones que relegan lo cubano al terreno de las emociones, a la vez que por omisión lo alejan del de la razón, conectando con la retórica propia de la moral europea colonial decimonónica, en función de la que se asociaba la negritud con las pasiones terrenales, excluyéndola de las virtudes racionales de supuesta tradición europea (Iniesta, 2009: 18).

\section{Conclusiones}

En el presente trabajo hemos analizado una muestra de la forma en la que RTVE representa la realidad cubana. Lejos de evocar una Cuba ideal, sí pretendemos cuestionar las ideas dominantes que se manejan acerca de su realidad, construidas mediante mensajes como los aquí analizados que, como se ha observado, tienen importantes sesgos ideológicos que se manifiestan en los aspectos de la realidad seleccionados para su retrato, así como en el encuadre mediante el que se les da sentido.

Los cuatro documentales analizados coinciden en la valoración negativa de todos los aspectos de la realidad sociopolítica cubana, de la que no se ofrece mayor explicación que la ineficiencia de las políticas socialistas del gobierno. Aquellos aspectos de la misma abordados de manera positiva coinciden siempre con la oferta de ocio o de acogida que esta nación brinda al español, bien como inmigrante, bien como turista. Conforme a esto, hemos distinguido dos tipos de representación clave de la realidad cubana: la "cárcel Cuba" y el "paraíso cuba".

El primero se construye aislando al país de su contexto histórico y geopolítico, tematizando el discurso hacia aspectos de su realidad sociopolítica claramente deficientes en comparación con los de una potencia económica, como pueden ser la ineficiencia de su industria, la frugalidad de la dieta de los cubanos o su limitado acceso a internet. De esta forma, analizando su realidad de forma descontextualizada, sin más referencia comparativa que la óptica primermundista del productor del documental, 
se retrata una sociedad presa en una gran cárcel de miseria a cargo de una oligarquía militar, cuya única salida es el abandono de la empresa socialista y la adopción de una democracia de mercado.

El segundo se configura principalmente resaltando la oferta de consumo turístico de la isla caribeña, entroncando con el retrato clásico que desde la industria de la publicidad se ha realizado de los países del Sur durante el siglo XX, con el componente peculiar en este caso del sentimiento nostálgico guardado hacia la última colonia del imperio perdido. En este sentido, se tiende a destacar la principal prueba del extinguido poderío español que supone esta isla "congelada en el tiempo", así como la especial calidez con la que sus habitantes reciben a sus ex-colonos.

La representación de este paraíso no está exenta, no obstante, de alusiones a la "cárcel" en la que vive su sociedad. El discurso político se manifiesta en los documentales turísticos en sintonía con la visión dominante de la «cárcel Cuba» antes descrita.

Así, entendemos que desde TVE se participa en la guerra mediática definida anteriormente contra Cuba, elaborando representaciones de su realidad en las que las agresiones estadounidenses al país caribeño se ven claramente minimizadas, cuando no directamente ignoradas. El prestigio y la voz privilegiada que se otorga a los movimientos de oposición al gobierno entronca con la política exterior norteamericana de apoyo financiero y mediático a los mismos, quedando las posiciones gubernamentales prácticamente obviadas.

De esta forma se retrata un país que, en supuesto periodo de paz, mantiene curiosamente medidas propias de un estado de sitio, debidas exclusivamente al carácter autoritario de su gobierno. La estrategia de encuadre adoptada por TVE en estos documentales permite representar a un país inmerso desde hace más de medio siglo en un conflicto de cuarta generación con la primera potencia mundial, obviando la realidad del conflicto mismo, lo que permite interpretar sus necesidades políticas conforme a la ideología liberal predominante.

\section{Referencias bibliográficas}

BALLESTEROS, M. A. (2014). "La evolución de los conflictos". En INSTITUTO ESPAÑOL DE ESTUDIOS ESTRATÉGICOS (coord.) (2014). Panorama geopolítico de los conflictos 2013. Ministerio de defensa. p. 9-27

CHOMSKY, N. (1992): Ilusiones necesarias. Control del pensamiento en las sociedades democráticas. Libertarias, Madrid.

FOJÓN, J.E. (2004).’Vigencia y limitaciones de la guerra de cuarta generación". En: Área: Seguridad y defensa, no 23/2006, Madrid: Real Instituto Elcano de estudios internacionales y estratégicos. p.1-6

FUEYO GUTIERREZ, A. (2002). De exóticos paraísos y miserias diversas, Barcelona: Icaria 
IGARTÚA, J.J; HUMANES, M.L. (2004). "Imágenes de Latinoamérica en la prensa española: una aproximación empírica desde la Teoría del Encuadre". En: Revista de comunicación y sociedad, vol. 17, $\mathrm{n}^{\circ}$ 1, Castellón: Universitat Jaume I. p.47-75

INIESTA, F. (2009). "El estigma de Cam: el negro en el pensamiento occidental". En CASTEL, A. (2009). Imaginar África: los estereotipos occidentales sobre África y los africanos. Madrid: Catarata. p. 11-34

LAMRANI, Salim, En Cuba, estado de sitio: las sanciones económicas de Estados Unidos contra La Habana. Una perspectiva histórica y jurídica. Sociedad Latina de Comunicación Social Tenerife - edición no venal, La Laguna. 2013.

LÓPEZ GARCÍA, G. (2001), La primera guerra mediática: la prensa en la guerra de Cuba. En Contacto interlingüístico e intercultural en el mundo hispano (dos vols.), Vol II, Valencia; Universidad de Valencia, p. 803 - 811.

LÓPEZ RADABÁN, P. (2010). "Nuevas vías para el estudio del framing periodístico: la noción de estrategia de encuadre". En: Estudios sobre el mensaje periodístico, $\mathrm{n}^{\mathrm{o}}$ 16, Castellón: Universitat Jaume I. p.235-258

MARTÍN SERRANO, M. (2004). La producción social de comunicación. Madrid: Alianza

SPENGLER, O. (1998). La decadencia de Occidente (dos vols.), Madrid: Espasa Calpe

W. SAID, S. (2002). Orientalismo, Madrid: Debate

Recursos web:

CENTRAL INTELLIGENCE AGENCY (2011). The World Factbook. Recuperado el 29/06/2014, de: https://www.cia.gov/library/publications/the-world-factbook/ fields/2103.html\#cu

EFE (2012). SIP nombró a Yoani Sánchez su vicepresidenta en Cuba. Recuperado el 23/06/2014, de http://www.el-nacional.com/mundo/SIP-Yoani-Sanchez-vicepresidenta-Cuba_0 78592763.html

FRANCO, M. (et al.) (2007). "Impact of Energy Intake, Physical Activity, and Population-wide Weight Loss on Cardiovascular Disease and Diabetes Mortality in Cuba, 1980-2005”. En: American journal of epidemiology, vol. 166, n²12, Baltimore: Johns Hopkins Bloomberg School of Public Health. p.1374-1380. Recuperado el 28/06/2014, de http://aje.oxfordjournals.org/content/166/12/1374.full. pdf + html 1374

LAMRANI, S. (2010). La diplomacia estadounidense y la disidencia cubana (1/2). Recuperado el 27/06/2014, de http://www.rebelion.org/noticia.php?id=119056

PRIMERA, M. (2014). Los planes de Estados Unidos. tras Zunzuneo: el Twitter cubano . El País. Recuperado el 20/06/2014, de http://internacional.elpais.com/ internacional/2014/04/03/actualidad/1396557398 859917.html.

RAVSBERG, F. (2009). UNICEF: Cuba sin desnutrición infantil. Recuperado el 24/06/2014, de http://www.bbc.co.uk/mundo/cultura_sociedad/2010/01/100126_1823_unicef_cuba_gz.shtml 
Recursos audiovisuales:

ESCUDERO, N. (1998). Cuba, directa al corazón [vídeo]: RTVE. Paraísos cercanos. Recuperado el 30/06/2014, de: http://www.rtve.es/alacarta/videos/paraisos-cercanos/paraisos-cercanos-cuba-directa-corazon/660262/

SACALUGA, J.A. (2006). Cuba, sombras y luces [vídeo]: RTVE. En Portada. Recuperado el 30/06/2014, de: https://www.youtube.com/watch?v=WGKAck_mdDY

PÉREZ. T. (2011). Españoles en el mundo: La Habana [vídeo]: RTVE. Españoles en el mundo. Recuperado el 30/06/2014, de: http://www.rtve.es/television/20110309/ espanoles-mundo-viaja-habana-tierra-ron-musica-habanos/415235.shtml

JIMÉNEZ PONS, J. (2012). Cuba, la revolución reinventada [vídeo]: RTVE. En Portada. Recuperado el 30/06/2014, de: http://www.rtve.es/alacarta/videos/ en-portada/portada-cuba-revolucion-reinventada/1359012/

\section{El autor}

Manuel González Ayestarán es licenciado en Ciencias de la Información por la Universidad Complutense de Madrid. Actualmente cursa el segundo año del máster oficial en Comunicación Social del Departamento de Sociología IV de esta misma universidad. Además, está culminando su Trabajo Fin de Máster y orientando sus investigaciones en aras de iniciar estudios de doctorado en Ciencias de la Información. 